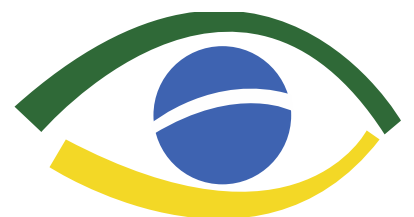

\section{Observatório da Uurisdiçãc Constitucional}

Observatório da Jurisdição Constitucional. Ano 7, no. 1, jan./jun. 2014. ISSN 1982-4564.

\title{
A Máxima da Proporcionalidade: um elemento estrutural do constitucionalismo global"
}

Matthias Klatt e Moritz Meister *

Tradução de João Costa Neto***

Resumo: Sob o plano de fundo do significado prático da máxima da proporcionalidade - o qual dificilmente pode ser superestimado -, o presente texto esclarece os cinco passos de aferição da proporcionalidade. Nesse sentido, a ênfase principal da apresentação recai sobre o sopesamento ou ponderação. Com base em novos resultados de pesquisa, apresentou-se e precisouse uma concepção com cuja ajuda o sopesamento - frequentemente percebido como difícil - pode ser racionalmente estruturado. Adicionalmente, o artigo fornece importantes conhecimentos elementares a respeito da discussão recente sobre a proporcionalidade, que também é controversa internacionalmente. Por fim, mostrou-se como se deve utilizar o argumento do nível reduzido de intensidade ou densidade de controle (reduzierte Kontrolldichte). Serve a título de exemplo, dentre outras, a decisão do Tribunal Constitucional Federal alemão (TCF) no caso Gustl Mollath.

Palavras-chave: $\quad$ princípio $\quad$ da
proporcionalidade; níveis de escrutínio; incomensurabilidade; ponderação; sopesamento.

\begin{abstract}
Abstrakt: Vor dem Hintergrund der kaum zu überschätzenden praktischen Bedeutung des Grundsatzes der Verhältnismäßigkeit erläutert der vorliegende Beitrag die fünf Schritte der Verhältnismäßigkeitsprüfung. Dabei liegt ein Schwerpunkt der Darstellung auf der Abwägung. Vorgestellt und anhand neuer Forschungsergebnisse präzisiert wird ein Konzept, mit dessen Hilfe die oft als schwierig wahrgenommene Abwägung rational strukturiert werden kann. Der Aufsatz vermittelt zudem wichtige Grundkenntnisse zur neueren, auch international kontrovers geführten Diskussion um die Verhältnismäßigkeit. Schließlich wird gezeigt, wie das Argument der reduzierten Kontrolldichte einzusetzen ist. Als Beispiel dient u.a. die Entscheidung des BVerfG im Fall Gustl Mollath.
\end{abstract}

Schliusselworte: $\quad$ Grundsatz der Verhältnismäßigkeit; Kontrolldichte; Abwägung; Inkommensurabilität.

\footnotetext{
* Este artigo foi originalmente publicado, em março de 2014 (Ano 54, Caderno 3, págs. 193-199), no periódico alemão Juristische Schulung (JuS), cuja finalidade precípua é oferecer conteúdo jurídico acurado e avançado, em uma linguagem acessível, aos estudantes universitários. Dentre os editores da JuS, encontra-se o atual Presidente do Tribunal Constitucional Federal alemão: Prof. Dr. Andreas Voßkuhle. O título original do artigo é: Der Grundsatz der Verhältnismäßigkeit. Ein Strukturelement des globalen Konstitutionalismus.

** O autor Matthias Klatt é Professor Titular de Direito Público, Europeu, Internacional Público e de Filosofia do Direito na Universidade de Hamburgo, Alemanha; no momento, ocupa temporariamente a Cátedra do Prof. Dr. Christoph Möllers na Humboldt-Universität zu Berlin. O autor Moritz Meister é advogado no escritório Wendelstein LLP, em Frankfurt am Main, Alemanha.

*** O tradutor é Doutorando em Direito Público pela Humboldt-Universität zu Berlin. Doutorando e Mestre em Direito, Estado e Constituição pela Universidade de Brasília (UnB). Mestrando em Direito Romano pela Faculdade de Direito do Largo de São Francisco, da Universidade de São Paulo (USP). Bacharel e Licenciado em Filosofia pela Universidade de Brasília (UnB). Bacharel em Direito pela Universidade Católica de Brasília (UCB). Professor Substituto de Direito Constitucional e de Direito Administrativo na UnB. Student Member da Society for the Promotion of Roman Studies (Fundada em 1910) e da Society for the Promotion of Hellenic Studies (Fundada em 1879). É, ainda, autor do livro "Dignidade Humana na visão do Tribunal Constitucional Federal alemão, do STF e do Tribunal Europeu de Direitos Humanos" (São Paulo: Saraiva, 2014).
} 


\section{Introdução}

A máxima da proporcionalidade pertence a um dos objetos mais importantes a serem estudados, em Direito Público, pelos bacharelandos em Direito. Isso tem bons motivos: em virtude de estar ancorada no Estado Democrático de Direito ${ }^{1}$ e nos Direitos Fundamentais ${ }^{2}$, a máxima irradia sobre todos os ramos do Direito ${ }^{3}$. Daí se origina seu significado central também para a atividade profissional dos operadores do Direito. Esse significado é ainda maior, porque a máxima da proporcionalidade é um dos "sucessos de exportação" da Ciência Jurídica alemã, além de possuir atrás de si uma trilha, internacional e única, de vitórias ${ }^{4}$. Ela foi recepcionada por várias ordens jurídicas ${ }^{5}$ e vale igualmente no Direito da União Europeia ${ }^{6}$ e na Convenção Europeia de Direitos Humanos ${ }^{7}$.

Nos últimos anos, a discussão internacional desenvolveu-se de modo particularmente turbulento. ${ }^{8} \mathrm{O}$ contexto deste desenvolvimento é a busca por características estruturais transnacionalmente válidas de Direito Público, assim como se coloca, em especial, na discussão sobre um "Constitucionalismo Global" . A máxima da proporcionalidade é um desses elementos estruturais essenciais.

\footnotetext{
1 BVerfGE 19, 342 (Nota de canto 17) = NJW 1966, 243; fundamental: Hirschberg, Der Grundsatz der Verhältnismäßigkeit, 1981; Grabitz, AöR 98 (1973), 568; no caso da literatura universitária, cf. Voßkuhle, JuS 2007, 429; Michael, JuS 2001, 654 ss., 764 ss. e 866 ss.

2 Alexy, Theorie der Grundrechte, 5. Auflage 2006, S. $100 \mathrm{ff}$.

${ }^{3}$ BVerfGE 7, 198 = NJW 1958, 257; cf., outrossim, BVerfGE 23, 127 (133) = NJW 1968, 979, acompanhado do comentário de Arndt: "regra diretiva açambarcante de toda ação estatal (,übergreifende Leitregel allen staatlichen Handelns")"; comparar o panorama apresentado em Grabitz, AöR 98 (1973), 568 (610-616). No caso da máxima da proporcionalidade como limite do poder punitivo estatal, cf. Weigend, Festschr. f Hirsch, 1999, p. 917 ss. Para uma crítica, cf., em particular, Schlink, Abwägung im Verfassungsrecht, 1976, p. 17-47.

${ }^{4}$ Klatt/Meister, Der Staat 51 (2012), 159 (160 ss.) com outras indicações; Saurer, Der Staat 51 (2012), 3.

${ }^{5}$ Sobre o caso do Reino Unido - onde vale algo semelhante, sobretudo desde o Human Rights Act de 1998 -, cf. Brady, Proportionality and Deference under the UK Human Rights Act, 2012; Kavanagh, Constitutional review under the UK Human Rights Act, 2009.

${ }^{6}$ Mayer, in: Grabitz/Hilf/Nettesheim, Das Recht der EU, 2013, Rdnrn. 403-406; Tridimas, The General Principles of EU Law, p. 136 ss.

${ }^{7}$ Rivers, Cambridge Law Journal 65 (2006), 174 (182 ss.).

${ }^{8}$ Cf. a assim chamada "controvérsia do International Journal of Constitucional Law" (controvérsia ICON): Tsakyrakis, International Journal of Constitutional Law 7 (2009), 468; Khosla, International Journal of Constitutional Law 8 (2010), 298; Tsakyrakis, International Journal of Constitutional Law (2010), 307; Klatt/Meister, International Journal of Constitutional Law 10 (2012), 687; Möller, International Journal of Constitutional Law 10 (2012), 709; dentre os textos monográficos mais recentes, cf., em especial, Barak, Proportionality, 2012; Klatt/Meister, The Constitutional Structure of Proportionality, 2012; Brady (n.r. 5).
}

${ }^{9}$ Klatt/Meister (n.r. 8), p. 171; Stone/Sweet/Mathews, Columbia Journal of Transnational Law 47 (2008), 72 (160); cf., outrossim, Saurer, Der Staat 51 (2012), 3. 
Este texto reconstrói a consolidada práxis decisória do Tribunal Constitucional Federal alemão (doravante, TCF) no que se refere a considerações sobre a proporcionalidade, bem como mostra suas estruturas fundamentais. No texto, mostram-se ainda quais especificidades devem ser observadas na resolução de um caso. A ênfase crucial recai sobre o último nível de aferição, o sopesamento ou ponderação, que também é denominado de proporcionalidade em sentido estrito.

Critica-se o sopesamento por ser um método marcadamente subjetivo, ensaístico e irracional $^{10}$; ele também é frequentemente vivenciado pelos estudantes de Direito desta maneira. Contudo, este texto evidencia como se pode, com a estrutura certa, ter êxito com o sopesamento; ademais, mostra como se pode estruturá-lo de maneira bastante racional.

\section{Fundamentos}

Direitos fundamentais são, assim como todos os princípios constitucionais, mandamentos de otimização ${ }^{11}$. Eles impõem que seu objeto seja realizado na medida mais ampla possível, de acordo com as circunstâncias fáticas e jurídicas dadas; que seja, portanto, otimizado. Deve haver a maior liberdade de expressão possível, o maior Estado Social possível, etc. A avaliação jurídica é, por conseguinte, uma questão de "mais-ou-menos". Desse modo, a aferição de princípios diferencia-se categoricamente da aferição de regras, a qual, enquanto subsunção, é uma questão de "tudo-ou-nada"12. A tarefa de um aplicador do Direito é determinar, no caso concreto, a medida constitucionalmente imposta de realização de um princípio constitucional.

A proporcionalidade é o melhor método para solucionar racionalmente colisões entre os objetivos de princípios contrapostos. Assim sendo, as etapas de aferição da adequação e da necessidade referem-se à otimização em face das circunstâncias fáticas do caso concreto. Por outro lado, a etapa de aferição do sopesamento ou ponderação refere-se à otimização em face das circunstâncias jurídicas do caso concreto. Estas últimas são definidas por meio dos princípios constitucionais colidentes. A equalização, na acepção de uma concordância prática, ocorre por meio do sopesamento ou ponderação.

\footnotetext{
${ }^{10}$ Schlink (n.r. 3), p. 79, 152 ss., 214-219; Habermas, Between Facts and Norms, 1996, p. 258; Webber, Canadian Journal of Law and Jurisprudence 23 (2010), 179.

${ }^{11}$ Alexy (n.r. 2), p. 75-77.

${ }^{12}$ Alexy, Ratio Juris 16 (2003), 433; Stück, ARSP 84 (1998), 405.
} 
A máxima da proporcionalidade é analisada em cinco passos (infra, III-VI) ${ }^{13}$. As duas primeiras etapas de aferição foram reunidas, neste texto, em um tópico (III). A estrutura de aferição é formal - ou seja, materialmente neutra -, o que implica sua aplicabilidade universal. Ela deve ser seguida lógica e forçosamente. Só assim estará internamente justificada a valoração de uma ação estatal como proporcional ou desproporcional.

Deve-se, porém, diferenciar dessa estrutura de justificação interna a assim chamada justificação externa ${ }^{14}$. Na justificativa externa, trata-se de fundamentar frases como "O meio $\mathrm{M}_{1}$ fomenta o objetivo almejado" ou "O meio alternativo $\mathrm{M}_{2}$ teria fomentado o objetivo mais robustamente”. Para essas justificativas externas, tem-se à disposição todo o arsenal de argumentos jurídicos. A correção material e a força persuasiva desses argumentos definem, se uma decisão sobre a proporcionalidade que segue a estrutura interna também se justifica externamente.

A diferenciação entre justificação interna e externa revela-se importante, dentre outros casos, no debate acerca da racionalidade e da objetividade da aferição de proporcionalidade. Com frequência, os críticos da máxima da proporcionalidade introduzem no debate as dificuldades e inseguranças argumentativas que se colocam no caso da justificativa externa. Contudo, fraquezas dos argumentos externos não podem falar, per se, contra a estrutura interna, pois esta é materialmente neutra. Ademais, essa diferença [entre justificativa interna e externa] desempenha um papel, quando se cuida do controle judicial da decisão sobre proporcionalidade tomada por um outro órgão. Esse controle deve sempre incluir integralmente a justificativa interna. Se o órgão que decidiu simplesmente não aferiu, por exemplo, a necessidade, a decisão já não se justifica internamente. Já no caso do controle da argumentação externa, a instituição de matizes ou gradações de níveis da intensidade do controle é não apenas concebível, como também comumente encontrada na prática. ${ }^{15}$

\footnotetext{
${ }^{13}$ Para a função da proporcionalidade no caso de deveres de proteção - ou seja, no caso da proibição de proteção insuficiente (Untermaßverbot) -, cf. Klatt, in: Klatt, Prinzipientheorie und Theorie der Abwägung, 2013, p. 34; Michael, JuS 2001, 764 (765-767). Este último texto aborda apenas a função da proporcionalidade no caso de direitos de defesa - ou seja, proibição do excesso (Übermaßverbot).

${ }^{14}$ A importante diferença entre justificação interna e externa referiu-se, até agora, apenas ao silogismo jurídico. Ela pode, entretanto, ser igualmente aplicada ao sopesamento ou ponderação e à proporcionalidade como um todo. Nesse sentido, cf. Klatt/Meister, Der Staat 51 (2012), 159 (172-174); ideia já defendida, pela primeira vez, em Klatt/Schmidt, Spielräume im Öffentlichen Recht, 2010, p. 13 ss.

${ }^{15}$ Sobre a gradação dos níveis de intensidade ou densidade do controle, cf., infra, VII.
} 


\section{Objetivo legítimo e meio legítimo}

\section{$\underline{\text { 1. Objetivo legítimo }}$}

A autoridade estatal que interfere em direitos de liberdade deve perseguir um objetivo legítimo com essa interferência ${ }^{16}$. A aferição consiste em dois passos: Em primeiro lugar, deve-se asseverar precisamente qual é o objetivo perseguido com a interferência, bem como se ele se identifica exatamente com a situação fática, isto é, com o suporte fático concreto (Sachverhalt). Em segundo lugar, deve-se efetuar uma avaliação da pergunta: este objetivo é juridicamente admissível? Nesse processo, ocorre apenas uma reflexão isolada acerca do próprio objetivo; a relação objetivo-meio não desempenha qualquer papel nessa fase. Nos exames universitários, quase sempre é de se afirmar a legitimidade do objetivo.

Há dois tipos de objetivos legítimos ${ }^{17}$. No caso dos assim chamados valores coletivos absolutos, trata-se de princípios constitucionais que são prescritos forçosamente às autoridades estatais. O Estado deve perseguir esses objetivos; é-lhe prescrito, por exemplo, proteger a liberdade de expressão, segundo o Art. 5, I, 1, da Lei Fundamental alemã. Por outro lado, a própria autoridade estatal estipula para si os assim chamados valores coletivos relativos, como, por exemplo, o legislador que faz uso de sua liberdade de conformação político-econômica $^{18}$. O pressuposto para tanto é a competência para definir objetivos ${ }^{19}$.

\section{Meio legítimo}

A aferição da legitimidade do meio também se dá isolada e abstratamente; e em dois passos. O meio efetivamente empregado deve ser precisamente designado e juridicamente avaliado. Em exames universitários, a legitimidade do meio encontra-se presente, em regra. Isso pode ocorrer, em especial, com respeito a uma norma pemissiva cuja consequência jurídica autoriza, em princípio, o emprego justamente do meio utilizado ${ }^{20}$. Segue-se, portanto, do $§ 15$ da Lei que regulamenta o direito de reunião (Versammlungsgesetz - VersG) que a dissolução de uma reunião enquanto meio é, em princípio, legítima. Em sentido oposto, um

\footnotetext{
${ }^{16}$ Problematiza a divisão entre objetivo e meio: Schlink (n.r. 3), p. 203-207.

${ }^{17}$ cf. Borowski, Grundrechte als Prinzipien, p. 187.

${ }^{18}$ BVerfGE 13, 97 (107) = NJW 1961, 2011.

${ }^{19}$ Instrutivo quanto à competência para definir objetivo: Grabitz, AöR 98 (1973), 568 (600-609).

${ }^{20}$ Cuida-se apenas de avaliar a consequência jurídica como, em princípio, legítima; e não de verificar a presença dos pressupostos fáticos da norma permissiva, isto é, dos pressupostos do suporte fático abstrato do fundamento legal autorizador (Tatbestandsvoraussetzungen der Ermächtigungsgrundlage).
} 
exemplo de meio ilegítimo tout court seria o emprego da pena de morte para perseguir o objetivo - legítimo - de redução dos custos da execução penal, pois implicaria violação do Art. 102 da Lei Fundamental.

\section{Adequação}

Os passos precedentes prepararam o terreno para a aferição da adequação. Um meio é adequado quando, com o seu auxílio, o objetivo perseguido pode ser fomentado ${ }^{21}$. O objetivo não precisa ser completamente satisfeito por meio do emprego do meio; um fomento é suficiente $^{22}$. Logo, também esse obstáculo é bastante baixo.

Exemplo: Inadequado era, por exemplo, que a Lei de Caça exigisse, para a caça com falcão, prova da habilidade para lidar com armas de fogo. Conhecimentos técnicos referentes a armas são irrelevantes para o exercício da falcoaria - caça que ocorre com a ajuda de uma ave de rapina - e, portanto, inadequados para o fomento do objetivo de exercer a caça de maneira mais ordenada ${ }^{23}$.

\section{Necessidade}

Diferentemente dos níveis de aferição precedentes, é recomendável fornecer esclarecimentos mais extensos no caso da necessidade. Na prática jurídica e nos exames universitários, há frequentemente casos em que se deve negar a presença da necessidade. Um meio é necessário, se não há outro meio igualmente adequado que interfira de maneira menos intensa no direito fundamental ${ }^{24}$.

A tarefa do aplicador do Direito consiste em buscar meios alternativos por meio dos quais o Estado também conseguiria alcançar o objetivo legítimo. Esses meios alternativos possuem natureza puramente hipotética. Eles não foram, de fato, implementados pelo Estado. Com frequência, a boa solução de um caso demanda que mais de um meio alternativo seja

\footnotetext{
${ }^{21}$ BVerfGE 96, 10 (23) = NVwZ 1997, 1109; 81, 156 (192) = NZA 1990, 161; cf. Hirschberg, Der Grundsatz der Verhältnismäßigkeit, 1981, p. 50-56.

${ }^{22}$ Sobre os problemas de determinação da medida correta de necessidade, cf. Gerards, International Journal of Constitutional Law 11 (2013), 466 (474-480).

${ }^{23}$ BVerfGE 55, $159(160)=$ NJW 1981, 673.

${ }^{24}$ BVerfGE 90, 145 (172) = NJW 1994, 1577; 77, 84 (109) = NJW 1988, 1195 = JuS 1988, 981 (Sachs); Hirschberg (n.r. 20), p. 56-75.
} 
concretamente designado e avaliado. Como a própria definição deixa claro, a necessidade possui dois pressupostos, que devem ser preenchidos cumulativamente. Em primeiro lugar, o meio efetivamente empregado deve fomentar ou promover o objetivo almejado, no mínimo, na mesma medida em que o teria feito o meio alternativo. Em segundo lugar, pode o meio efetivamente empregado levar, no máximo, a uma interferência tão intensa sobre o princípio constitucional restringido quanto o emprego - hipotético - do meio alternativo. Assim sendo, para a aferição da necessidade, é preciso determinar e - conforme o caso - comparar os efeitos do meio alternativo hipotético e do meio efetivamente empregado, tanto no que se refere à persecução do objetivo legítimo quanto à restrição do princípio constitucional.

Se houver vários meios igualmente adequados e restritivos, a autoridade estatal possui a assim chamada discricionariedade para escolher meios [ou margem de conformação para escolher meios]: a autoridade pode escolher livremente entre esses meios ${ }^{25}$. No caso concreto, a avaliação acerca do preenchimento, ou não, dos pressupostos da necessidade pode ser bastante difícil. Frequentemente, o último recurso para auxiliar na decisão é recorrer às discricionariedades avaliativa e apreciativa [ou margens de conformação avaliativa e apreciativa; Einschätzungs- und Beurteilungsspielraum], conferidas pelo TCF ao legislador, em especial, para a apreciação de circunstâncias fáticas incertas ${ }^{26}$.

Exemplo: O Direito dos Alimentos [ramo híbrido entre o Direito do Consumidor e o Direito da Segurança Alimentar e Nutricional] proibia de maneira absoluta a venda de alimentos que, não sendo feitos de chocolate, pudessem ser confundidos com chocolate pelo consumidor. $\mathrm{O}$ autor da reclamação constitucional [que levou seu caso ao TCF] teve negado o direito de colocar à venda bonecos de natal ou coelhos de páscoa feitos de arroz tufado. $\mathrm{O}$ objetivo legítimo de evitar a confusão do consumidor também poderia ter sido alcançado, na mesma medida, por meio da obrigação de identificar e etiquetar adequadamente o produto. Acresça-se que a obrigação de rotulagem oferece, quando comparada com a proibição da venda, uma restrição menor à liberdade profissional do fornecedor. Por conseguinte, a proibição da venda não era necessária ${ }^{27}$.

\footnotetext{
${ }^{25}$ Sobre a discricionariedade ou margem de conformação para escolher meios, cf. Klatt, in: Klatt (n.r. 13$)$, p. 34 (58 ss.); Alexy, A Theory of Constitutional Rights, 2002, p. 396.

${ }^{26}$ Trata-se da assim chamada discricionariedade ou margem de conformação epistêmica; para uma abordagem ampla sobre o tema, cf. Klatt/Schmidt (n.r. 14). Comparar, outrossim, com o tópico VI, infra.

${ }^{27}$ BVerfGE 53, 135 = NJW 1980, 1565.
} 


\section{Sopesamento [ou ponderação]}

O último nível de aferição da proporcionalidade é o sopesamento [ou ponderação], que também é chamado de proporcionalidade em sentido estrito. A racionalidade do sopesamento enquanto método é particularmente controvertida ${ }^{28}$.

\section{Relevância na análise de casos}

Para além das diferenças terminológicas, há uma difundida concordância quanto ao sopesamento ser o núcleo central da aferição da proporcionalidade, assim como onipresente e ubíquo no Direito em geral ${ }^{29}$. Durante a graduação, o sopesamento possui um significado proeminente nas tarefas e nos exames universitários. Isso não vale apenas para as provas relacionadas aos direitos fundamentais, como no caso da reclamação constitucional. ${ }^{30} \mathrm{Na}$ verdade, o sopesamento desempenha um papel central em todo o Direito Administrativo, em especial no escrutínio de decisões discricionárias.

O elevado significado de uma aferição racional e bem estruturada do sopesamento na atribuição de notas em tarefas universitárias é explicado precisamente pelo fato de o sopesamento oferecer elevados desafios ao candidato: por exemplo, enquanto com frequência, no caso da aferição da admissibilidade de recursos jurídicos, deve-se “apenas" lidar com os

\footnotetext{
${ }^{28}$ Schlink (n.r. 3), p. 79, 152 ss., 214-219; Habermas, Between facts and norms, 1996, p. 258; Webber, Canadian Journal of Law and Jurisprudence 23 (2010), 179. Para uma discussão sobre essa crítica, cf. Klatt/Meister, Der Staat 51 (2012), 159 (161-162); Klatt/Meister, International Journal of Constitutional Law 10 (2012), 687, assim como as contribuições em Klatt (n.r. 13).

${ }^{29}$ Schauer, in: Klatt, Institutionalized Reason, 2012, p. 307-316; Alexy, Ratio Juris 16 (2003), 433 (436).

${ }^{30}$ Nota do tradutor: Traduziram-se as expressões "Aufsichtsarbeiten" e "Examina" por "tarefas" e "exames universitários", respectivamente. Na verdade, há muitas sutilezas - sobre as quais não é necessário falar em pormenor - que a tradução simplesmente deixa de lado. Registre-se, porém, que, na Alemanha, há dois Exames de Estado (Staatsexamina). A nota nos exames (Examina) - sobretudo aquela alcançada no segundo - define a profissão que o bacharel em Direito poderá seguir. Há uma semelhança com o Exame da Ordem dos Advogados do Brasil (OAB), no Brasil. Contudo, na Alemanha, os exames são condição para o acesso não apenas à carreira da advocacia, mas também às do Ministério Público e da Magistratura. Além disso, os Examina são verdadeiros certames públicos, aplicados e regulados pelo próprio Estado, embora cada estado federado da Alemanha possua regras específicas. Em outras palavras, uma vez que o texto é voltado para universitários, os autores dão conselhos de como se deve utilizar corretamente a proporcionalidade nos exames universitários. Esclareça-se, igualmente, que se optou por traduzir "Verfassungsbeschwerde" por "reclamação constitucional". Trata-se, porém, de um termo de difícil tradução. Literalmente, pode-se traduzir por "reclamação constitucional". Alguns preferem a expressão "recurso constitucional". Contudo, a natureza jurídica da Verfassungsbeschwerde é de ação e não de recurso, na acepção técnico-processual do termo. Assinale-se, ainda, que tampouco se trata de incidente processual. De qualquer sorte, trata-se do instrumento jurídico que pode ser manejado por qualquer pessoa (jedermann) contra ato, comissivo ou omissivo, que viole, atual e diretamente (gegenwärtig und unmittelbar), direito fundamental ou direito equiparado a fundamental (grundrechtsgleiches Recht). A Verfassungsbeschwerde guarda semelhanças com o recurso de amparo do direito espanhol, ao qual ela é, até certo ponto e guardadas as devidas proporções, análoga.
} 
densos e cada vez mais enriquecidos problemas referentes aos pressupostos de admissibilidade, o que realmente importa, no caso do sopesamento, é apresentar uma argumentação racional, persuasiva e coerente. Porém, para muitos alunos, falta a estrutura basilar. Por isso, sopesamentos são frequentemente vistos como imprecisos e arbitrários.

Essas inseguranças têm origem no imenso número de casos, e não em uma preparação insuficiente para a prova. Elas baseiam-se, na verdade, no fato de decisões de sopesamento exigirem uma grande competência argumentativa dos aplicadores do Direito em geral, e não apenas dos estudantes ou dos recém-formados. Amiúde, é preciso sopesar uma pluralidade de valores constitucionais contrapostos, e o sopesamento é, na maioria das vezes, a bússola decisiva para o resultado que soluciona o caso.

\section{A estrutura do sopesamento}

Sopesamentos convincentes e consistentes pressupõem uma estrutura lógica. Robert Alexy apresentou, em 1985, uma estrutura desse tipo na sua "Teoria dos Direitos Fundamentais", que, nesse ínterim, foi publicada em 6 idiomas e que alcançou proeminência internacional $^{31}$. Essa estrutura pode, em essência, ser interpretada como uma reconstrução analítica da prática decisória do TCF: a teoria do sopesamento de Alexy revela o que acontece implicitamente na justificação de qualquer decisão de sopesamento.

Nos últimos anos, a estrutura fundamental do sopesamento foi ampliada, por meio de reflexões teóricas complexas, com o auxílio de fórmulas matemáticas que sublinham a estrutura lógica do processo de sopesamento ${ }^{32}$. Esses conhecimentos serão adaptados a seguir, na forma de um guia para a estruturação da aferição do sopesamento, que é útil tanto para tarefas e exames quanto para a prática profissional.

\section{a) Os três passos do sopesamento}

Sopesamentos devem assegurar que os ônus advindos de uma intervenção estatal não sejam desproporcionais em face do objetivo almejado. Quanto mais intensa for a interferência sobre o direito fundamental, maiores deverão ser as exigências constitucionais para a justificação da interferência. Mais precisamente: quanto mais intensa a interferência sobre o

\footnotetext{
${ }^{31}$ Alexy (n.r. 2).

${ }^{32}$ Alexy, in: Jickeli/Kreutz/Reuter, Gedächtnisschr. ss. Jürgen Sonnenschein, p. 771 ss.; Klatt/Schmidt (n.r. 14); Klatt/Meister (n.r. 8); Acerca do significado da teoria de Alexy, cf., p.ex., Barak (n.r. 8), p. 5.
} 
direito fundamental, maiores deverão ser as exigências quanto à importância do objetivo perseguido $^{33}$.

Segue-se dessa ideia fundamental que todos os sopesamentos consistem em três fases de aferição. Em primeiro lugar, deve-se determinar a intensidade da interferência no caso concreto. Em segundo lugar, deve-se debater sobre quão importante no caso concreto é o fim perseguido por meio da interferência. E em terceiro lugar, deve-se aferir, considerando a relação entre as duas primeiras classificações, se a importância do objetivo pode justificar a intensidade da interferência. Apenas a separação clara desses três passos já conduz a um ganho considerável de transparência e racionalidade. Ela compele a uma estruturação da argumentação e a uma revelação ou divulgação dos argumentos relevantes. Em particular, pode-se evitar que argumentos referentes à intensidade da interferência sejam considerados na determinação da importância do objetivo, e vice-versa.

\section{b) A escala triádica}

Para a classificação da intensidade da interferência e da importância do objetivo, devese recorrer a uma escala triádica com os níveis leve, moderado e sério ${ }^{34}$. Assim, a retenção breve de uma pessoa por parte de uma autoridade policial representa, em linhas gerais, uma interferência leve sobre o direito fundamental à liberdade da pessoa, consoante o Art. 2, II, da Lei Fundamental. Ao contrário, uma pena privativa de liberdade que dure anos possui peso concreto sério. A importância do objetivo almejado deve ser avaliada da mesma forma. Uma retenção apenas por diversão seria não-importante. Por outro lado, uma retenção para a proteção da vida e da integridade de outras pessoas seria classificada como seriamente importante.

Tanto a classificação da intensidade da interferência como a determinação da importância do objetivo almejado referem-se sempre (e apenas) ao caso concreto. Elas pressupõem decisões valorativas e argumentação moral. Este é o momento de trazer à tona, em pormenor, os argumentos normalmente desenvolvidos para os casos concretos ou suportes fáticos concretos (Sachverhalten) das tarefas ou exames. A questão referente ao fato de as decisões valorativas e os argumentos morais trazidos para a estrutura formal do sopesamento

\footnotetext{
${ }^{33}$ Esta é a assim chamada primeira lei do sopesamento, Alexy (n.r. 2), p. 146.

${ }^{34}$ Klatt/Meister (n.r. 8), p. 12 ss.
} 
serem materialmente convincentes, ou não, diz respeito à justificação externa da decisão de sopesamento; e não à interna ${ }^{35}$.

\section{c) $O$ resultado do sopesamento}

Se o grau de intensidade da intervenção e a importância do objetivo perseguido estiverem estabelecidos, cumpre investigar, no terceiro passo, se a importância do objetivo perseguido pode justificar a intensidade da interferência. Isto sempre será simples, quando o grau da intensidade da interferência e a importância do objetivo almejado forem avaliadas distintamente na escala triádica. Uma interferência leve estará justificada, por exemplo, por objetivos com peso concreto sério. Ao invés, se a importância do objetivo almejado for menor do que a intensidade da interferência, a interferência não estará justificada.

Interessantes são aquelas situações em que a intensidade da intervenção e a importância do objetivo almejado são classificadas no mesmo nível. Trata-se dos conjuntos leve/leve, moderado/moderado e sério/sério. Nestes casos, há uma situação de impasse, que conduz a uma margem de conformação do legislador ${ }^{36}$. O TCF contém-se a si próprio e não pode estabelecer uma violação constitucional.

\section{Novos desenvolvimentos}

A ferramenta apresentada até aqui já permite estruturar e precisar uma decisão de sopesamento, uma vez que compele ao desvelamento e à ordenação dos argumentos relevantes para a decisão. Conforme demonstram novos resultados de pesquisa, a estrutura fundamental do sopesamento pode ser sofisticada ainda mais, de modo a abranger especificidades adicionais do caso concreto ${ }^{37}$. Por motivos de simplificação, isso não deve ser aprofundado aqui. A ideia fundamental dessas ampliações pode, contudo, ser rapidamente compreendida, além de ser extremamente útil para o caso concreto. Trata-se, em particular, de dois aspectos, os quais podem ser relevantes em qualquer sopesamento: o peso abstrato de princípios colidentes e a segurança cognitiva das premissas adotadas no sopesamento.

\footnotetext{
${ }^{35}$ Klatt/Meister, Der Staat 51 (2012), 159 (172-174).

${ }^{36}$ Klatt/Meister (n.r. 8), p. 13; elementar a respeito: Alexy, in: Alexy (n.r. 24), p. 388 (394-414).

${ }^{37}$ A respeito, cf. os artigos em Klatt (n.r. 13).
} 
A finalidade de um sopesamento tão racional quanto possível pode exigir a atribuição de pesos abstratos aos princípios colidentes ${ }^{38}$. Isso torna-se relevante sobretudo quando os pesos abstratos divergem. O peso abstrato é o significado que o princípio possui independentemente do caso concreto ${ }^{39}$. Quanto maior for o peso abstrato, maior será a chance de o princípio sobrepor-se, no sopesamento, diante de um princípio colidente ${ }^{40}$. É possível atribuir, por exemplo, um peso abstrato maior aos direitos fundamentais do que a princípios que não sejam direitos fundamentais. Por sua vez, poder-se-ia atribuir um peso abstrato maior à dignidade humana do que ao direito geral de ação, previsto no Art. 2 I da Lei Fundamental.

Se se diferencia dessa maneira entre os pesos abstratos, então surge o seguinte efeito: princípios com um peso abstrato maior obtêm uma espécie de "margem de vitória" ou "vantagem prévia" (winning margin; Abwägungsvorsprung) no sopesamento; ou, ainda, uma preferência prima facie em face de princípios com peso abstrato menor. Não há uma decisão prévia definitiva acerca do resultado do sopesamento, porquanto o sopesamento ainda depende dos pesos dos princípios no caso concreto $^{41}$. Entretanto, a diferença de pesos abstratos conduz a uma distribuição de ônus argumentativos e justificativos ${ }^{42}$. Para a solução do caso, isso implica a tendência de que um princípio constitucional só conseguirá sobreporse, em face de um princípio com maior peso abstrato, a um custo argumentativo maior, baseado na intensidade da interferência no caso concreto. A vantagem prévia do princípio com peso abstrato maior deve ser compensada a um custo argumentativo maior, se, por exemplo, o direito geral de ação desejar manter-se diante da dignidade humana em um sopesamento ${ }^{43}$.

Também há um ganho de racionalidade, quando se observa a segurança cognitiva das premissas utilizadas para atribuir os pesos. As exigências quanto à segurança das premissas que fundamentam uma interferência crescem na proporção da intensidade da inteferência ${ }^{44}$. Interferências intensas só podem ser justificadas, se o caso concreto com base no qual ocorre

\footnotetext{
${ }^{38}$ Isso quer dizer Michael quando alude ao primeiro passo em: Michael, JuS 2001, 654 (659).

${ }^{39}$ Acerca disso e do que se segue: Klatt/Meister, Der Staat 51 (2012), 159 (165-167).

${ }^{40}$ Esta é a assim chamada segunda lei de primazia ou prioridade (zweite Vorranggesetz). cf. Klatt/Meister, Der Staat 51 (2012), 159 (166).

${ }^{41}$ Klatt/Meister, Der Staat 51 (2012), 159 (166).

${ }^{42}$ No mesmo sentido: Michael, JuS 2001, 654 (659).

${ }^{43}$ Para uma análise detalhada do sopesamento quanto à dignidade humana, cf. Klatt/Meister (n.r. 8), p. 29-42, 66-68; Teifke, Das Prinzip Menschenwürde, 2011.

${ }^{44}$ Em pormenor: Klatt/Schmidt (n.r. 14); Klatt/Schmidt, in: Klatt (n.r. 13), p. 105.
} 
a interferência estiver delineado de maneira suficientemente segura. Essa figura argumentativa deve ser levada em conta em decisões de sopesamento, quando - e sempre que - isto se mostrar relevante no caso concreto. Essa argumentação é tipicamente importante em decisões referentes a prognósticos para a defesa de riscos futuros, como no âmbito do Direito Ambiental e do Direito de Engenharia Genética.

\section{Exemplo: O caso Mollath}

A aplicação dos níveis de aferição e do paradigma argumentativo descritos acima será esclarecida por meio da decisão do TCF no caso Gustl Mollath ${ }^{45}$.

Caso concreto ou suporte fático concreto: O Sr. Mollath foi demandado perante o Tribunal de Justiça local e, em 2006, foi absolvido com base na sua inimputabilidade nãoescusatória durante o cometimento dos crimes [a culpabilidade não-escustória ou nãoexcludente (nicht ausschließender Schuldunfähigkeit) implica o que se chamaria no Brasil de absolvição imprópria, porquanto ao réu será aplicada medida de segurança]. Com a absolvição, o Tribunal de Justiça determinou, conforme o $§ 63$ do Código Penal alemão (StGB), que o Sr. Mollath fosse internado em um hospital psiquiátrico. Durante o curso dos anos, os Tribunais Superiores determinaram o prosseguimento dessa internação. A reclamação constitucional do Sr. Mollath volta-se contra isso.

O motivo determinante para a decisão do TCF, que estabeleceu a inconstitucionalidade do prosseguimento da internação, foi a máxima da proporcionalidade. O TCF enfatiza, primeiramente, a necessidade do sopesamento: “(43)... A relação de tensão entre a pretensão de liberdade do indivíduo envolvido e a necessidade de segurança por parte da coletividade perante as esperadas e consideráveis violações a bens jurídicos exige uma equalização justa e plausível”. Ademais, o Tribunal explica que, no caso da internação, cuida-se de uma “(36)... interferência profunda no direito fundamental do reclamante à liberdade da pessoa, extraído do Art. 2, II, 2, da Lei Fundamental". O Tribunal avaliou, pois, a intensidade da interferência como séria, na escala triádica. Nesse contexto, o TCF mostra, ainda, o grande peso abstrato do direito fundamental à liberdade previsto no Art. 2, II, 2, da Lei Fundamental, uma vez que concede ao direito, independentemente do caso concreto, “(38)... uma posição elevada entre os direitos fundamentais". O Tribunal também ressalta que uma longa internação anda, lado a

\footnotetext{
${ }^{45}$ BVerfG, NJW 2013, 3228.
} 
lado, com uma pretensão de liberdade que se torna cada vez mais forte: “(47)... Quanto mais longa for a internação em um hospital psiquiátrico, mais rigorosos serão os pressupostos para a proporcionalidade da privação de liberdade."

A partir da classificação da intensidade da interferência como séria e com a ênfase do elevado peso abstrato do direito fundamental à liberdade, a régua para uma possível justificação da interferência foi colocada em patamar superior. No segundo passo do sopesamento, é necessário aferir a importância do objetivo perseguido. Já que a interferência ocorreu no mais alto nível da escala triádica (sério), apenas uma importância do objetivo perseguido igualmente elevada e de mesmo nível poderia legitimar a interferência. Nas palavras do Tribunal: são necessários "motivos especialmente fortes". O TCF identifica tais motivos na "proteção da coletividade", a qual se expressa por meio do Direito Penal e do Direito Processual Penal ${ }^{46}$.

Assim, tanto a intensidade da interferência quanto a importância do objetivo perseguido foram colocadas no mais alto nível da escala triádica. Logo, configurou-se, na verdade, uma situação de impasse. O resultado teria sido não declarar a inconstitucionalidade, em virtude da margem de conformação ou discricionariedade das instâncias inferiores [que são os Tribunais Superiores especializados que haviam analisado o caso]. Contudo, o TCF trouxe à tona, adicionalmente, o aspecto referente à segurança cognitiva das premissas da interferência: A função assecuratória da liberdade do Art. 2, II, 2, da Lei Fundamental exige “(40)... que decisões concernentes à privação de liberdade se baseiem em um esclarecimento judicial da matéria que seja suficiente ... e, desde um ponto de vista fático, sobre fundamentos bastantes", e isso no sentido do “(42)... mandamento do melhor esclarecimento possível do caso concreto". As decisões dos Tribunais Superiores falharam precisamente neste ponto. Não se procedeu a um prognóstico concreto da periculosidade do Sr. Mollath, e certas circunstâncias atenuantes não foram consideradas na decisão ${ }^{47}$. Se se considerar que essas inseguranças cognitivas do caso concreto pesam contra a força do objetivo legítimo, então este último passa a ter menos valor. Isso porque, ao mesmo tempo, a segurança cognitiva quanto à força da ingerência sobre o direito fundamental à liberdade permanece possivelmente elevada. Portanto, o direito fundamental à liberdade sobrepõe-se no resultado

\footnotetext{
${ }^{46}$ Sobre esse parágrafo, cf., em especial: BVerfG, NJW 2013, 3228 (Nota de canto 39).

${ }^{47}$ BVerfG, NJW 2013, 3228 (nota de canto 50 ss.).
} 
do sopesamento. A segurança das premissas é aqui, assim como na decisão sobre a Lei de Segurança Aérea ${ }^{48}$, a pequena e decisiva diferença que faz inclinar a balança.

\section{$\underline{\text { 5. Os três problemas do sopesamento }}$}

A teoria do sopesamento aqui apresentada é veementemente criticada, tanto no Direito Constitucional alemão quanto no debate internacional. Dentre os numerosos pontos dignos de discussão, foram ressaltados a seguir três novos argumentos dos opositores do sopesamento, que representam um conhecimento basilar e central acerca do sopesamento. Todas as três objeções são, contudo, refutáveis.

\section{a) O problema da preferência}

Às vezes se critica que os sopesamentos enfraquecem a força normativa dos direitos fundamentais. Sopesam-se, em pé de igualdade, direitos fundamentais garantidos constitucionalmente com interesses ancorados não-constitucionalmente. Logo, os direitos fundamentais poderiam subordinar-se a esses interesses não-constitucionalmente garantidos. De resto, a posição de preferência ou primazia dos direitos fundamentais seria inteiramente colocada de lado, incluindo a respectiva força normativa e a tutela eficaz dos direitos fundamentais ${ }^{49}$.

Essa crítica diz respeito a um ponto legítimo. Se os direitos fundamentais colidentes fossem colocados no sopesamento em face de outros interesses sem qualquer posição de preferência, então os direitos fundamentais poderiam, contínua e facilmente, ser colocados de lado por outros interesses; e, dessa forma, perderiam, de fato, força efetiva. Este perigo pode, contudo, ser confrontado por meio da diferenciação dos pesos abstratos [ou força em abstrato]. É possível atribuir aos direitos fundamentais um peso abstrato mais elevado em face de princípios que não são direitos fundamentais e, por conseguinte, dar-lhes uma primazia ou preferência abstrata, no sentido de uma vantagem prévia. Quanto maior for o peso [abstrato] atribuído, tanto maior será a probabilidade de o direito fundamental sobrepor-se em um sopesamento. Por meio desse efeito, o poder efetivo dos direitos fundamentais no sopesamento é protegido, sem uma prioridade absoluta dos direitos fundamentais em face de princípios que não são direitos fundamentais, o que implicaria um sistema quase absoluto de

\footnotetext{
${ }^{48}$ cf. BVerfGE 115, 118 (156 ss.); em pormenor, a respeito: Klatt/Schmidt (n.r. 14), p. 33-37.

49 Tsakyrakis, International Journal of Constitutional Law 7 (2009), 468; Rusteberg, Der grundrechtliche Gewährleistungsgehalt, 2009, p. 71.
} 
direitos fundamentais ${ }^{50}$. A primazia ou preferência prima facie dos direitos fundamentais oferece uma proteção efetiva dos direitos fundamentais.

\section{b) O problema da objetividade}

Critica-se, além disso, que o sopesamento despertaria a aparência enganadora de ser objetivo, neutro e desprovido de valorações e argumentos morais. Todavia, sopesamentos contêm, efetiva e tipicamente, problemas morais difíceis, os quais seriam encobertos ${ }^{51}$.

Deve-se admitir essa crítica, no que se refere a sopesamentos não poderem ser obtidos sem valorações e argumentos morais. No caso da justificação externa, valorações e argumentos morais vêm à baila forçosamente. As avaliações da intensidade das interferências e dos pesos [do objetivo perseguido] não podem ser feitas sem considerações morais. Porém, simplesmente não se pode afirmar que o sopesamento encobre tais considerações. Muito ao contrário, o sopesamento torna, por meio da diferença entre justificação interna e externa, exata e especialmente transparentes aquelas premissas que devem ser justificadas externamente $^{52}$. O sopesamento só é neutro na exata medida em que sua estrutura formal for suficiente. Essa estrutura deve necessariamente ser preenchida com argumentos baseados em pesos e permeados moral e axiologicamente ${ }^{53}$. É precisamente a vantangem do sopesamento desvelar esses argumentos, o que possibilita uma maior transparência, rastreabilidade e racionalidade da avaliação ou aferição jurídico-constitucional.

c) O problema das maçãs-e-laranjas

Muitos acreditam que o sopesamento sucumbe diante do "problema das maçãs-elaranjas”. Princípios constitucionais frequentemente são incomparáveis; e, em particular, não são mensuráveis por meio de uma escala comum ${ }^{54}$. Esse problema, da assim chamada

\footnotetext{
${ }^{50}$ Klatt/Meister, Der Staat 51 (2012), 159 (164-167).

${ }^{51}$ Tsakyrakis, International Journal of Constitutional Law 7 (2009), 468 (474-475); idem, International Journal of Constitutional Law 8 (2010), 307 (308).

${ }^{52}$ Klatt/Meister, Der Staat 51 (2012), 159 (173).

${ }^{53}$ Klatt/Meister, Der Staat 51 (2012), 159 (174).

${ }^{54}$ Finnis, in: George, Natural Law Theory, 1992, p. 134 (146, 151); Aleinikoff, Yale Law Journal 96 (1987), 943 (972 ss.); Zucca, Constitutional Dilemmas, 2007, p. 55-60, 85 ss.
} 
incomensurabilidade, é - também no âmbito internacional - uma das objeções mais importantes contra o sopesamento ${ }^{55}$.

A objeção chama a atenção para uma dificuldade que se coloca frequentemente na prática jurídica. Em casos complexos, a avaliação na escala triádica requer uma argumentação elaborada, que certamente pode ser discutida e criticada. Apesar disso, essas dificuldades não representam qualquer argumento contra o sopesamento. Elas são, ao invés, o motivo pelo qual empreender uma avaliação dos princípios na estrutura do sopesamento ${ }^{56}$, conquanto o sopesamento pressuponha, de fato, uma escala triádica a ser aplicada aos dois princípios colidentes. No entanto, para a comparação entre princípios basta uma escala ordinal, isto é, uma escala que use os três níveis acima mencionados - leve, moderado, sério - ; e que, destarte, institua relações entre intensidades de interferência e importâncias, colocando estes dois em relação um com o outro. Uma escala cardinal - uma, portanto, que confere um valor pontual e matematicamente exato a todo aspecto individual; e, dessa forma, estabelece uma comensurabilidade perfeita - é simplesmente desnecessária para a comparação entre princípios $^{57}$. Com efeito, princípios podem ser comparados, mesmo quando forem incomensuráveis $^{58}$. De resto, o problema das maçãs-e-laranjas não é, portanto, qualquer obstáculo aos sopesamentos; mas sim o seu ponto de partida. Estabelecer a comparabilidade por meio de sopesamento, sobretudo em casos difíceis, é exatamente a tarefa imposta pela Constituição ao aplicador do Direito ${ }^{59}$.

\section{O argumento coringa dos níveis de intensidade do controle}

Um gerenciamento diferenciado do nível de intensidade de controle possui especial significado para a aferição da proporcionalidade ${ }^{60}$. Conforme a relação específica de controle presente no caso concreto, os argumentos dos atores estatais comissivos deverão ser avaliados com rigor diferenciado. Nos exames universitários, o nível de intensidade ou densidade do controle pode ser inserido como um "argumento coringa". Neste particular, é relevante não ir

\footnotetext{
55 Tsakyrakis, International Journal of Constitutional Law 7 (2009), 468 (471); em sentido contrário: Klatt/Meister, International Journal of Constitutional Law 10 (2012), 687.

${ }^{56}$ Também nesse sentido: Afonso da Silva, in: Klatt (n.r. 13), p. 236 (246).

${ }^{57}$ Em pormenor a esse respeito: Klatt/Meister (n.r. 8), p. 58-66.

${ }^{58}$ Afonso da Silva, in: Klatt (n.r. 13), p. 236 (269 ss.).

${ }^{59}$ Millgram, in: Chang, Incommensurability, Incomparability, and Practical Reason, 1997, p. 151.

${ }^{60}$ Voßkuhle, JuS 2007, 429 (430 ss.).
} 
muito direito ao ponto; e apenas trazer à tona considerações acerca do nível de intensidade do controle após uma discussão cuidadosa dos argumentos contidos no caso concreto. É possível, teoricamente, problematizar o nível de intensidade do controle em todos os cinco níveis de aferição da proporcionalidade. Na prática, porém, convém ingressar nessa questão, sobretudo, no que concerne à necessidade e ao sopesamento.

Já estabelecida é a diferenciação entre três diferentes intensidades de controle. No controle intensificado de conteúdo, o próprio TCF examina erros dos Tribunais Superiores no que tange à determinação do caso concreto e à interpretação do direito ordinário, de maneira independente e pormenorizada ${ }^{61}$. De intensidade moderada é o controle de plausibilidade ${ }^{62}$. Uma avaliação um pouco mais branda ocorre no caso do mero controle à evidência ${ }^{63}$. A escolha de uma intensidade de controle específica deve ser fundamentada no caso concreto. Nesse sentido, é possível recorrer aos critérios de intensidade da interferência no direito fundamental ${ }^{64}$ ou de insegurança cognitiva quanto a decisões baseadas em prognósticos ${ }^{65}$.

\section{Considerações finais}

A máxima da proporcionalidade possui, para a análise de casos em todo o Direito Público, uma relevância que dificilmente pode ser superestimada. Ela deve ser aferida em cinco passos. Uma margem de conformação avaliativa da autoridade estatal pode ser obtida a partir da aplicação de um controle de intensidade reduzida. O emprego desse "argumento coringa" só deve ocorrer após a discussão cuidadosa de outros argumentos; portanto, apenas depois do final das considerações sobre aquela respectiva etapa de aferição. $\mathrm{O}$ sopesamento pode ser racionalmente estruturado com a ajuda de três passos e uma escala triádica. Para tanto, é preciso levar em conta complementarmente os pesos abstratos e a segurança das premissas, nos casos concretos.

\footnotetext{
${ }^{61}$ BVerfGE 82, 43 (Nota de canto 27) = NJW 1990, 1980; 60, 79 (Nota de canto 42) = NJW 1982, 1379; 42, 163 $(169)=$ NJW 1976, 1680 .

${ }^{62}$ BVerfGE 57, 139 (Nota de canto 75) = NJW 1981, 2107; 30, 250 (263) = NJW 1971, 1603; 25, 1 (12 ss., 17) = NJW 1969, 499.

${ }^{63}$ BVerfGE 125, 175 (Nota de canto 141) = NJW 2010, $505=\mathrm{JuS} 2010,844($ Ruland $) ; 40,196(223)=$ NJW 1976,$179 ; 36,1(17)=$ NJW 1973, 1539.

${ }^{64}$ BVerfGE 61, 1 (Nota de canto 10) = NJW 1983, 1415, com considerações de der Decken, NJW $1983,1400$.

${ }^{65}$ BVerfGE 50, 290 (Nota de canto 110) = NJW 1979, 699.
} 
No discurso sobre um constitucionalismo global - que se encontra atualmente em desenvolvimento -, a máxima da proporcionalidade assume uma posição destacada ${ }^{66}$. Ela apresenta-se como elemento nuclear de uma ciência que transcende aos ordenamentos jurídicos individuais, sobretudo em Direito Público. Logo, a proporcionalidade - como apenas poucos objetos do Direito Público alemão - é até mesmo adequada, para preparar para atividades profissionais internacionais. A formação jurídica deveria concentrar-se de maneira essencialmente mais robusta do que tem ocorrido até agora sobre tais estruturas nucleares que são de extrema relevância -, com o simultâneo abandono do conhecimento detalhista e enciclopédico ${ }^{67}$.

Artigo recebido em 29 de maio de 2014. Artigo aprovado para publicação em 29 de maio de 2014.

DOI: $10.11117 / 1982-4564.07 .02$

\footnotetext{
${ }^{66}$ Klatt/Meister (n.r. 8), p. 171; Beatty, The Ultimate Rule of Law, 2004, p. 162; Schlink, in: Rosenfeld/Sajó, The Oxford Handbook of Comparative Constitutional Law, p. 718 (736); Barak (n.r. 8).

${ }^{67}$ cf. Wissenschaftsrat, Perspektiven der Rechtswissenschaft in Deutschland, 2012, p. 8, 60-62.
} 